Irène Studer-Rohr · Josef Schlatter $\cdot$ Daniel R. Dietrich

\title{
Kinetic parameters and intraindividual fluctuations of ochratoxin A plasma levels in humans
}

\begin{abstract}
The mycotoxin ochratoxin A (OTA) is a rodent carcinogen produced by species of the ubiquitous fungal genera Aspergillus and Penicillium. OTA is found in a variety of food items and as a consequence is also found in human plasma (average concentrations found in this study: $0.1-1 \mathrm{ng}$ OTA $/ \mathrm{ml}$ plasma). To improve the scientific basis for cancer risk assessment the toxicokinetic profile of OTA was studied in one human volunteer following ingestion of $395 \mathrm{ng}^{3} \mathrm{H}$-labeled OTA $(3.8 \mu \mathrm{Ci})$. A two-compartment open model consisting of a central compartment was found to best describe the in vivo data. This two-compartment model consisted of a fast elimination and distribution phase $\left(\mathrm{T}_{1 / 2}\right.$ about $\left.20 \mathrm{~h}\right)$ followed by a slow elimination phase (renal clearance about $0.11 \mathrm{ml} / \mathrm{min}$.) and a calculated plasma half-life of 35.55 days. This half-life was approximately eight times longer than that determined previously in rats. In addition, the intraindividual fluctuation of OTA plasma levels was investigated in eight individuals over a period of 2 months. The concentrations determined ranged between 0.2 and $0.9 \mathrm{ng}$ OTA $/ \mathrm{ml}$ plasma. The plasma levels in some individuals remained nearly constant over time, while others varied considerably (e.g. increase of
\end{abstract}

\footnotetext{
D. R. Dietrich $(\square)$

Department of Environmental Toxicology,

University of Konstanz, Jacob-Burckhardtstr. 25,

78457 Konstanz, Germany

e-mail: Daniel.Dietrich@uni-konstanz.de

Tel.: +49-7531-883518; Fax: +49-7531-883170

I. Studer-Rohr · D. R. Dietrich

Institute of Toxicology,

Swiss Federal Institute of Technology

and University of Zurich,

8603 Schwerzenbach, Switzerland

\section{J. Schlatter}

Toxicology Section, Division of Food Science,

Swiss Federal Office of Public Health, Zurich, Switzerland

I. Studer-Rohr

Department of Food Science,

Swiss Federal Institute of Technology,

CH-8092 Zurich, Switzerland
}

$0.4 \mathrm{ng} / \mathrm{ml}$ within 3 days, decrease of $0.3 \mathrm{ng} / \mathrm{ml}$ within 5 days) during the observation period. This intraindividual fluctuation in OTA plasma levels, which may represent differences in OTA exposure and/or metabolism, as well as the large difference in plasma half-life in humans compared to rats must be taken into consideration when the results of rat cancer study data are extrapolated to humans for risk assessment purposes.

Key words Ochratoxin A $\cdot$ Kinetics $\cdot$ Humans . Plasma levels · Cancer risk extrapolation

\section{Introduction}

The mycotoxin ochratoxin A (OTA) is produced by ubiquitous Penicillium and Aspergillus species. Food and feed contamination by the toxin is found mainly in countries with a temperate or continental climate. Data regarding the widespread contamination of agricultural commodities and animal products by OTA have been published widely over the past few years. For review and additional data see International Agency for Research on Cancer (IARC) (1993), Kuiper-Goodman and Scott (1989) and Trucksess et al. (1999).

The main target organ of OTA toxicity in several animal species is the kidney (Kuiper-Goodman and Scott 1989). In addition, OTA has been demonstrated to be a highly potent renal carcinogen in rats (Boorman 1989). IARC has classified ochratoxin A as "possibly carcinogenic to humans" (IARC 1993). Ochratoxin in human serum was first looked for in the Balkan area (Hult et al. 1982; Petkova-Bocharova et al. 1988) because it was thought to be a major factor contributing to the induction of Balkan endemic nephropathy (BEN) and urothelial tract tumors (UTT). Indeed, the results of a recent epidemiological study suggest that the occurrence of BEN and UTT are highly correlated and that the occurrence of the diseases coincides with high OTA exposure (Nikolov et al. 1996). Extensive studies were undertaken and a large number of samples of human 
Table 1 Occurrence of OTA in blood

\begin{tabular}{lcclll}
\hline Country & $\begin{array}{l}\text { No. of } \\
\text { samples }\end{array}$ & $\begin{array}{l}\text { Positive } \\
\text { samples }(\%)\end{array}$ & $\begin{array}{l}\text { Detection } \\
\text { limit }(\mathrm{ng} / \mathrm{ml})\end{array}$ & $\begin{array}{l}\text { Content } \\
(\mathrm{ng} / \mathrm{ml})\end{array}$ & Reference \\
\hline Canada & 159 & 40 & No indication & $0.27-35.33^{\mathrm{a}}$ & $\begin{array}{l}\text { Frohlich et al. 1991 } \\
\text { Czechoslovakia }\end{array}$ \\
Denmark & 143 & 25 & 0.1 & $0.1-1.26^{\mathrm{a}}$ & $\begin{array}{l}\text { Fukal and Reisnerova 1990 } \\
\text { Germany }\end{array}$ \\
Italy & 306 & 54 & 0.1 & $0.1-13.2^{\mathrm{a}}$ & Hald 1991 \\
& 133 & 100 & 0.05 & $0.05-14.0^{\mathrm{a}}$ & Bauer and Gareis 1987 \\
Poland & 138 & 97 & 0.05 & $0.12-57.2^{\mathrm{a}}$ & Breitholz-Emanuelsson et al. 1994 \\
Palli et al. 1999 & $0.27^{\mathrm{a}, \mathrm{b}}$ & Golinski et al. 1991 \\
Sweden & 1065 & 7 & 1.0 & $0.3-6.7^{\mathrm{a}}$ & Breitholz et al. 1991 \\
Switzerland & 297 & 13 & 0.3 & $0.09-0.94^{\mathrm{c}}$ & Breitholz-Emanuelsson et al. 1993 \\
\hline
\end{tabular}

\footnotetext{
${ }^{\text {a }}$ Serum or plasma

${ }^{\mathrm{b}}$ Mean of all samples measured
}

${ }^{\mathrm{c}}$ Blood

blood from this region were analysed. Between $6 \%$ and $26 \%$ of the samples contained OTA in the range of 1-35 ng OTA $/ \mathrm{ml}$ blood (Petkova-Bocharova et al. 1988) and 1-40 ng OTA $/ \mathrm{ml}$ serum (Hult et al. 1982). In studies carried out in other countries, OTA has been found in most human blood samples (see Table 1), when sensitive analytical methods have been used, and OTA levels in areas endemic for BEN and UTT do not appear to be significantly higher than those found in healthy adults elsewhere in the world.

The daily intake of OTA in humans via food can be calculated based on a relatively good database concerning OTA concentration in food items (DFG 1990; Rühl et al. 1992; Studer-Rohr et al. 1995). However, at present human cancer risk evaluation based on extrapolation from animal data is difficult, as large species differences are known to exist; for example, plasma halflives determined in various species range from $0.68 \mathrm{~h}$ in fish to $510 \mathrm{~h}$ in monkeys (Hagelberg et al. 1989; Li et al. 1997). One of the main factors influencing plasma halflife is the capacity of OTA to bind to plasma proteins, which appears to differ among species (Chang and Chu 1977; Galtier et al. 1979; Hagelberg et al. 1989). Consequently the values for renal clearance may also differ considerably (Hagelberg et al. 1989; Li et al. 1997).

It was therefore the aim of the present study to determine the kinetic parameters of OTA in a human volunteer as well as to investigate the intraindividual fluctuations of human OTA plasma concentrations in order to produce a better base for OTA cancer risk assessment in humans.

\section{Material and methods}

\section{Chemicals}

OTA, phosphate-buffered saline (PBS), $\mathrm{pH} 7.4$, and bovine serum albumin (BSA) were purchased from Sigma (St. Louis Mo.), sodium chloride (p.a. Art. 71380), chloroform (p.a. Art. 25690) and ammonium hydroxide (p.a. Art. 9860) were purchased from Fluka Chemie (9470 Buchs, Switzerland). Acetic acid 100\% (p.a. Art. 100063), ethanol (p.a. Art. 100983) and orthophosphoric acid minimum 85\% (p.a. Art. 573) were from Merck (Darmstadt, Germany), methanol 205 was from Romil Chemicals (Loughbor- ough, UK) and the immunoaffinity columns were from Biocode (York, UK). ${ }^{3} \mathrm{H}$-labeled OTA was purchased from Moravek Biochemicals (Brea, Calif.). The scintillation cocktails for unoxidized and oxidized samples were Ready Gel and Monophase 40, respectively, and were purchased from Beckman (USA) and Packard.

Methods

\section{Chemical analysis of plasma}

The analyses were carried out according to the method of Zimmerli and Dick (1995). Up to $2 \mathrm{ml}$ of human plasma was mixed with $10 \mathrm{ml} 2 \mathrm{M} \mathrm{NaCl}$ solution containing $34 \mathrm{ml} 85 \% \mathrm{H}_{3} \mathrm{PO}_{4} / 1$. After the addition of $5 \mathrm{ml}$ chloroform the mixture was shaken for $2 \mathrm{~min}$ and then centrifuged at $2500 \mathrm{~g}$ for $20 \mathrm{~min}$. The organic phase was transferred into a flask and the extraction with chloroform was repeated an additional three times. The combined organic phases were evaporated to dryness. The residue was dissolved in $4 \times 5 \mathrm{ml}$ PBS $/ 15 \%$ methanol (v/v). This solution was applied to an immunoaffinity column (IAC) and pushed through the column using low pressure $(1-2 \mathrm{ml} / \mathrm{min})$.

The column was washed with $10 \mathrm{ml}$ distilled water and airdried. The PBS/methanol and the water were discarded. OTA, now bound to the IAC was then eluted from the column with $3 \mathrm{ml}$ $100 \%$ methanol. The OTA containing methanol was evaporated in a waterbath $\left(40^{\circ} \mathrm{C}\right)$ under a nitrogen stream. The residue was taken up in 50-100 $\mu \mathrm{l}$ of methanol and analysed by HPLC (for HPLC conditions see Table 2).

\section{Radiochemical purity of ${ }^{3} \mathrm{H}-\mathrm{OTA}$}

The radiochemical purity of the labeled OTA was tested by HPLC and by IAC/HPLC analyses. Uniformly labeled ${ }^{3} \mathrm{H}-\mathrm{OTA}(25 \mathrm{nCi}$, about $2.5 \mathrm{ng}$, specific activity $3.9 \mathrm{Ci} / \mathrm{mmol}$ ) spiked with $13.4 \mathrm{ng}$ unlabeled OTA was injected into the HPLC system. The HPLC eluate was collected at 1-min intervals and the amount of radioactivity of each sample was determined in a liquid scintillation counter (LS 6000 LL Beckman, USA). The unlabeled and labeled OTA were detected by fluorescence and quantified by peak area integration. The HPLC fraction with the highest amount of radioactivity was again injected into the HPLC system and the same steps as in the first HPLC run were repeated to detect loss of ${ }^{3} \mathrm{H}$ label.

Further testing for radiochemical purity was carried out using an OTA IAC. Labeled OTA $(25 \mathrm{nCi})$ spiked with $50 \mathrm{ng}$ unlabeled OTA was mixed with $20 \mathrm{ml} \mathrm{PBS} / 15 \%$ methanol (v/v) and the solution was poured onto the column. The IAC was then rinsed with $10 \mathrm{ml}$ distilled water and the OTA was eluted with $3 \mathrm{ml}$ methanol. The PBS/methanol and water fractions were collected in $5-\mathrm{ml}$ samples and the amount of radioactivity was determined by scintillation counting. The amount of radioactivity in the eluate was 
Table 2 HPLC conditions employed

\begin{tabular}{ll}
\hline Instrument & Kontron HPLC Systems 600 \\
\hline Column & Spherisorb ODS $25 \mu \mathrm{m}, 250 \times 4 \mathrm{~mm}$, \\
& Knauer Säulentechnik $(\mathrm{Germany})$ \\
Precolumn & Spherisorb ODS $25 \mu \mathrm{m}, 30 \times 4 \mathrm{~mm}$, \\
& Knauer Säulentechnik $($ Germany) \\
Column temperature & $50{ }^{\circ} \mathrm{C}$ \\
Injection volume & $20-50 \mu \mathrm{l}$ \\
Eluent (isocratic) & $65 \% \mathrm{methanol}, 35 \%$ water $/$ acetic acid $(91: 9 \mathrm{v} / \mathrm{v})$ \\
Post-column alkalinization & $25 \%$ ammonium hydroxide, $0.2 \mathrm{ml} / \mathrm{min}$ \\
Flow & $1.0 \mathrm{ml} / \mathrm{min}$ \\
Detection & Fluorescence detector $($ Merck F 1000 \\
& fluorescence spectrophotometer $)$ \\
Excitation wavelength & $390 \mathrm{~nm}$ \\
Emission wavelength & $440 \mathrm{~nm}$ \\
Detection limit for standards $(\mathrm{S} / \mathrm{N}=2)$ & 4 pg OTA \\
\hline
\end{tabular}

determined by counting two aliquots of $20 \mu$ l. The amounts of unlabeled and radioactive OTA in the eluate were also determined by HPLC analysis after injection of two aliquots of $20 \mu \mathrm{l}$. The HPLC fraction during the OTA elution time was collected for determination of the amount of radioactivity. The remainder of the IAC eluate was reapplied to the IAC column, eluted and analysed by HPLC, as described above. This reapplication procedure was repeated twice. The whole experiment including three IAC reapplications was carried out in triplicate.

\section{Radiochemical stability of ${ }^{3} \mathrm{H}-\mathrm{OTA}$}

Uniformly labeled OTA $(2.5 \mathrm{nCi})$ spiked with $3.4 \mu \mathrm{g}$ unlabeled OTA was mixed either with $2.5 \mathrm{ml}$ PBS, pH 7.4, or with $2.5 \mathrm{ml}$ PBS, pH 7.4, with $0.1 \%$ BSA. These solutions were kept for $1,4,7$ and 21 days at $37{ }^{\circ} \mathrm{C}$. At the end of the respective incubation periods the solutions were acidified with $10 \mu \mathrm{l}$ concentrated $\mathrm{HCl}$, and OTA was extracted twice with $1 \mathrm{ml}$ chloroform. The solutions were then centrifuged for $20 \mathrm{~min}$ at $2000 \mathrm{~g}$ to separate the phases. Aliquots of the chloroform phase $(100 \mu \mathrm{l})$ and of the aqueous phase $(1 \mathrm{ml})$ were taken out and the amount of radioactivity was determined in a liquid scintillation counter. The percentage of radioactivity found in the aqueous phase was calculated from the ratio of radioactivity found in the PBS and chloroform phases. The concentration of unlabeled OTA was not analysed.

Experimental design of human studies

All of the experiments with human subjects were communicated to the Swiss Federal Office of Public Health, Department Radiation Safety, for approval, and were carried out in compliance with the ethical standards of the Declaration of Helsinki.

\section{Determination of kinetic parameters}

${ }^{3} \mathrm{H}$-labeled OTA $(3.8 \mu \mathrm{Ci})$ was dissolved in pure ethanol (corresponding to $395 \mathrm{ng}$ OTA) and ingested by a male volunteer (age 57 years, weight $62 \mathrm{~kg}$, height $163 \mathrm{~cm})$. Blood samples $(9-18 \mathrm{ml})$ were taken at $8,13,24,36$ and $58 \mathrm{~h}$ and at $3,4,6,9,13,20,33,54$ and 75 days after ingestion. Complete daily urine samples were collected for the first 4 days. Thereafter, urine samples were collected on days when blood samples were taken (see above), with the exception of day 13. The blood was centrifuged, plasma was separated and the plasma and the blood corpuscles (erythrocytes etc.) stored at $-20{ }^{\circ} \mathrm{C}$ until analysis. After determining the volume of the urine, it was also stored at $-20{ }^{\circ} \mathrm{C}$ until analysis. Aliquots of each plasma and urine sample $(0.2-1 \mathrm{ml}$ and $1-2 \mathrm{ml}$, respectively) were counted in a liquid scintillation counter.

Eight plasma samples $(0.2-2.0 \mathrm{ml})$ and four urine samples $(2 \mathrm{ml})$ were analysed using the IAC/HPLC method as described previously. In addition to the latter protocol, all samples were spiked with unlabeled OTA. After the extraction of the plasma with chloroform, $2.5 \mathrm{ml}$ of the aqueous phase was taken for analysis of radioactivity. All fractions from the IAC including the PBS methanol and water fractions were collected for analysis of radioactivity. From the IAC methanol eluate (total $3 \mathrm{ml}$ ), $1 \mathrm{ml}$ was taken directly for liquid scintillation counting. The other $2 \mathrm{ml}$ was evaporated to dryness, dissolved in $100 \mu \mathrm{l}$ methanol and $50 \mu \mathrm{l}$ was injected into the HPLC system. The HPLC eluate was collected in 2-min fractions and the radioactivity was determined by liquid scintillation counting. The recovery of unlabeled OTA was calculated by integrating the peak area of the HPLC analysis.

The amount of radioactivity in the blood corpuscles was determined by liquid scintillation counting with previous oxidation (Packard Oxidizer 306) of 200-500 $\mu$ l of each sample.

\section{Intraindividual fluctuation of OTA plasma levels}

The OTA levels in the plasma from eight volunteers (four females and four males, age 26 to 57 years) were determined over a period of 8 weeks. In the first week blood samples were taken every second day, and thereafter at weekly intervals. Blood samples were centrifuged, and plasma and erythrocytes separated and stored at $-20{ }^{\circ} \mathrm{C}$ until analysis. Generally, sample extracts were analysed twice for each time-point. For one volunteer (male no. 3, the results from whom showed the greatest fluctuations) double sample analyses were carried out.

\section{Calculations}

The plasma elimination half-life of OTA was approximated by describing the experimental data with an exponential expression representing the kinetics typical of a two-compartment model consisting of a central compartment (Klaassen 1986):

$\mathrm{y}(t)=\mathrm{Ae}^{-\alpha t}+\mathrm{Be}^{-\beta t}$

where $\mathrm{y}(t)$ is the plasma concentration at time $t$ (Fig. 1), A and B are the concentration axis intercepts in the semilogarithmic plot of the plasma concentration/time curve of the residual line and the extrapolated curve of the $\beta$ phase (Fig. 1, inset) while $\alpha$ and $\beta$ are the elimination constants of the $\alpha$ and $\beta$ phase, respectively. The residual line resulted from the differences between the measured concentrations during the $\alpha$ phase and the corresponding extrapolated concentrations of the $\beta$ phase. The corresponding half-lives were calculated from (Klaassen 1986):

$\mathrm{T}_{1 / 2 \alpha}=\ln 2 / \alpha$

$\mathrm{T}_{1 / 2 \beta}=\ln 2 / \beta$

The elimination rate constant, $\mathrm{k}_{\mathrm{el}}$ (including the rate constant between the two compartments and the excretion), is described by the following equation (Klaassen 1986): 


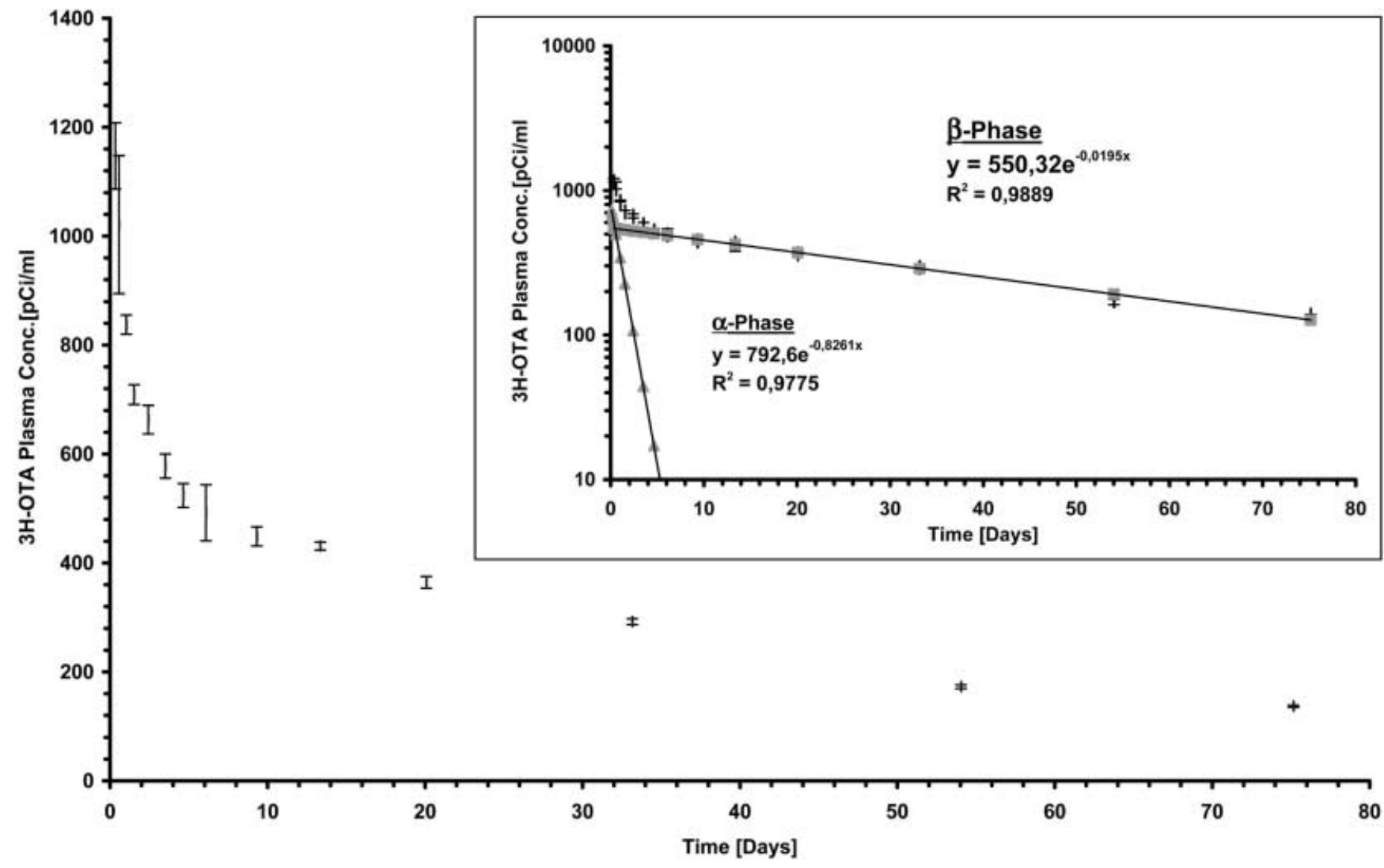

Fig. 1 Linear plot of the ${ }^{3} \mathrm{H}$-OTA concentration in plasma $(\mathrm{pCi} / \mathrm{ml})$ versus time (days) (inset plots and linear regressions of the two elimination phases obtained by assuming a two-compartment model consisting of a central compartment). The numerical values calculated for the model parameters were: $\mathrm{A}=792.6 \mathrm{pC} \mathrm{i} \cdot \mathrm{ml}^{-1} \cdot \mathrm{day}^{-1} ; \alpha=$ $-0.8261 ; \mathrm{B}=550.32 \mathrm{pCi} \cdot \mathrm{ml}^{-1} \cdot \mathrm{day}^{-1} ; \beta=-0.0195$

$\mathrm{k}_{\mathrm{el}}=\alpha \beta(\mathrm{A}+\mathrm{B}) /(\alpha \mathrm{B}+\beta \mathrm{A})$

The renal clearance of radioactivity can be calculated from the following expression (Klaassen 1986):

$\mathrm{Cl}=(\mathrm{U} \times \mathrm{V}) / \mathrm{P}$

where $\mathrm{Cl}$ is the clearance of the radioactivity, $\mathrm{U}$ the concentration of radioactivity in the urine, $\mathrm{P}$ the concentration of radioactivity in the plasma and V the volume of urine per time. However, this calculation of clearance could be employed only if the following conditions were met: (a) there was a reliable and stable estimate of the plasma concentration of OTA, (b) the extent of OTA protein binding was known, and (c) the urinary concentration of the parent OTA was known. The present experimental set-up and the data derived thereof did not meet these conditions and consequently prohibited the use of the above equation. Renal clearance was therefore approximated by plotting the urinary excretion rate $(\Delta \mathrm{U} /$ $\Delta t$ ) over a time period $(\Delta \mathrm{T})$ versus the mid-plasma concentrations of OTA (Fig. 2). The slope of the linear regression through these data points equals the approximate average renal clearance.

\section{Results}

Analytical methods

The detection limit of OTA in plasma using the IAC/ HPLC method was $0.05 \mathrm{ng} / \mathrm{ml}(\mathrm{S} / \mathrm{N}=3)$. The recovery of plasma OTA from the IAC was $\geq 80 \%$. The IACs were regenerated with $20 \mathrm{ml}$ PBS and were used repeatedly up to ten times without a significant decrease in OTA retention. Reproducibility within and between the IACs was good, as indicated by a maximal standard deviation of $10 \%$ of the arithmetic mean of double analyses (range of OTA levels measured $0.1-1.0 \mathrm{ng} / \mathrm{ml}$ ).

Repetitive HPLC analyses demonstrated high reproducibility of OTA determinations: the maximal standard deviation between double analyses did not exceed $10 \%$ of the respective arithmetic mean.

\section{Radiochemical purity and stability of ${ }^{3} \mathrm{H}-\mathrm{OTA}$}

No chromatographic differences were observed in the HPLC determinations between unlabeled and labeled OTA. The ratio of unlabeled to labeled OTA remained approximately constant in all extraction, elution and analysis steps of the IAC/HPLC method. Triple primary purification with IAC showed the presence of a maximal $2 \%$ of tritiated water. This tritiated water was not detectable in subsequent IAC elutions of the primary IAC eluate. It was therefore concluded that with the methods available the radiochemical purity of the labeled OTA used was greater than $98 \%$. The labeled OTA was therefore considered of sufficient radiochemical purity to be employed for the kinetic study in the human volunteer without the necessity for additional purification steps (for further experimental details see Studer-Rohr, 1995). 


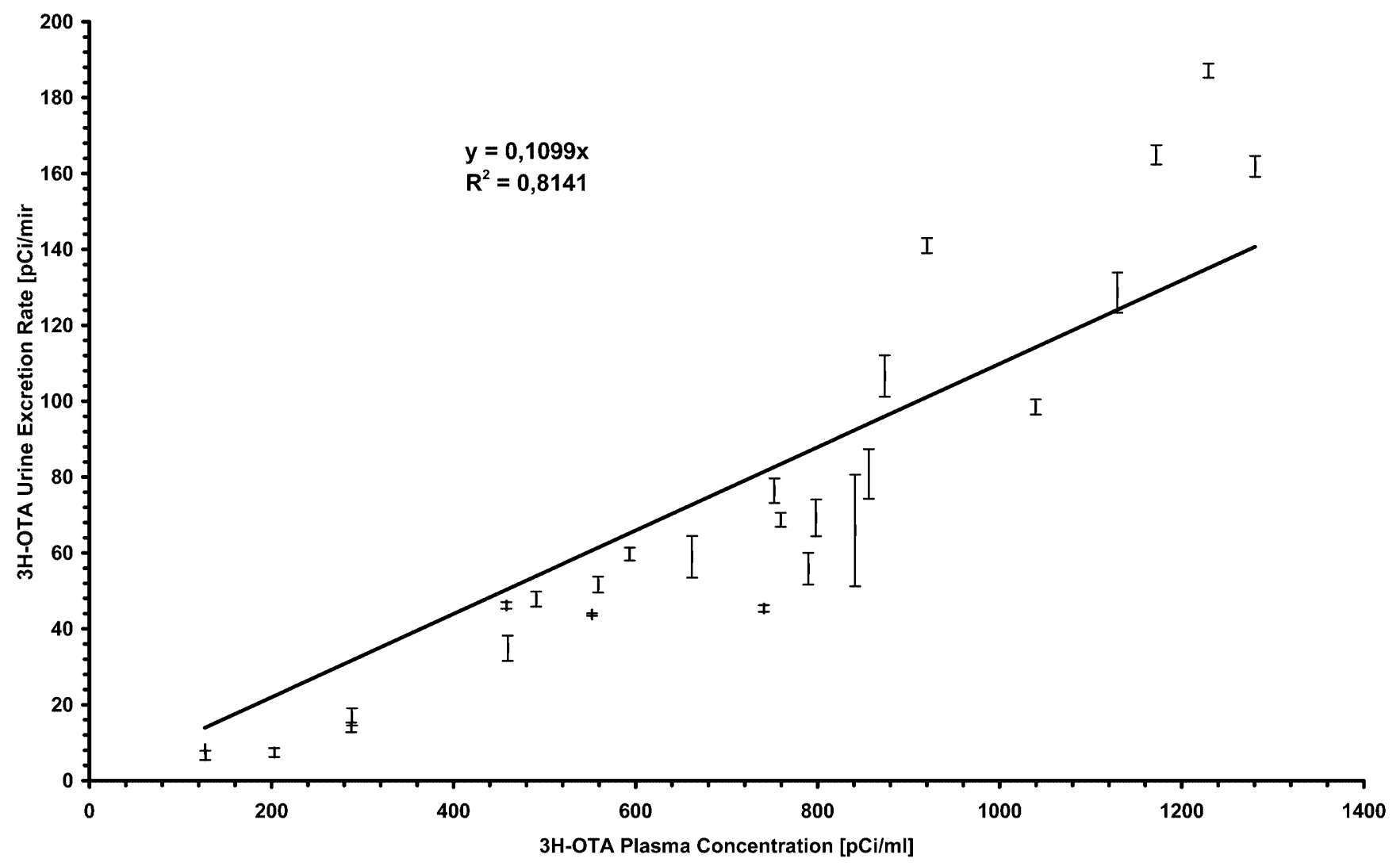

Fig. 2 Linear plot of the ${ }^{3} \mathrm{H}$ excretion rate $(\mathrm{pCi} / \mathrm{min})$ versus the midplasma levels of ${ }^{3} \mathrm{H}$-OTA. The slope of the linear regression equals the renal clearance of radioactivity, i.e. $\mathrm{Cl}=0.1099 \mathrm{ml} \cdot \mathrm{min}^{-1}$

Incubation of labeled OTA in PBS for 21 days at $37^{\circ} \mathrm{C}$ and $\mathrm{pH} 7.4$ resulted in a slight but significant increase in tritiated water from originally $1 \%$ on day 1 to a maximum of $3 \%$ on day 21 . The addition of BSA to PBS resulted in a stabilization of OTA, i.e. no significant increase in tritiated water was observed between day 1 $(1.6 \%)$ and $21(2.0 \%)$. This observation may be explained by a stabilizing effect of proteins on the OTA molecule, which otherwise degrades in alkaline medium and in the presence of water (T.J. Jansen, Vicam, USA; R. Dick, Swiss Federal Office of Public Health, Switzerland; personal communications). OTA has also been demonstrated to bind to human plasma proteins (Hagelberg et al. 1989). It was therefore assumed that human plasma proteins would stabilize the radiolabeled OTA in a comparable fashion as determined with BSA in vitro. Accordingly, the radiochemical stability of the labeled OTA was found to be sufficient for in vivo experimentation.

\section{Determination of kinetic parameters}

The change in radioactivity in the plasma after ingestion of $3.8 \mu \mathrm{Ci}$ radiolabeled OTA ( $395 \mathrm{ng}$ OTA) is shown in Fig. 1 (and Fig. 1, inset). Assuming a plasma volume of
2.81 , the plasma concentrations found $8 \mathrm{~h}$ after ingestion would represent $84.5 \%(3.21 \mu \mathrm{Ci})$ of the total administered dose. A fast decrease in the mean plasma concentrations was observed during the first 6 days, representing a change from $84.5 \%(3.21 \mu \mathrm{Ci})$ to $36.3 \%(1.38 \mu \mathrm{Ci})$ of the total administered dose. In contrast, only a very slow decrease in plasma radioactivity occurred thereafter.

Based on these observations, a two-compartment model consisting of a central compartment was postulated. The plasma half-life of ${ }^{3} \mathrm{H}$-OTA was calculated to be approximately $20.13 \mathrm{~h}$ during the first 6 days $\left(\alpha\right.$ phase, Fig. 1 inset). The plasma half-life of ${ }^{3} \mathrm{H}$-OTA during the $\beta$ phase (from day 6 onwards) was calculated to be 35.55 days.

To determine whether or not the measured radioactivity in the plasma consisted of unchanged OTA and/or radiolabeled metabolites, plasma samples obtained on days $1(13 \mathrm{~h}), 3(84 \mathrm{~h}), 6,9,20,33,54$ and 75 were analysed by IAC/HPLC. In comparison with the fraction distributions obtained with aqueous standards (OTA purity experiments), no significantly elevated radioactivity levels were found in the aqueous phase following chloroform extraction of the plasma samples. Nor could unexpectedly elevated radioactivity levels be demonstrated in the PBS/methanol and water fraction after passing through the IAC. Subsequent HPLC analyses of the respective fractions did not demonstrate any other peaks than the OTA peak, suggesting that OTA metabolites in the plasma were either absent or at undetectable levels. 
Despite some fluctuations of the resulting concentrations, the levels, that is the curve form of radioactivity determined in the blood corpuscles (after oxidation, recovery from the oxidizer $\geq 95 \%$ ), were comparable to those obtained with plasma (data not shown). If peak values (most likely outliers) were not taken into account the radioactivity determined in blood corpuscles ranged between $4 \%$ and $10 \%$ of the radioactivity found in the respective plasma samples.

The excretion rate of radioactivity in the urine is shown in Fig. 3. During the first 6 days of the experiment, $0.77 \mu \mathrm{Ci}$ (approximately $20 \%$ of the original initial dose) was excreted in the urine. In the following days (days 6-75) $1.61 \mu \mathrm{Ci}$ was excreted via the urine, accounting at the end of the experimental period for more than $2.37 \mu \mathrm{Ci}$ or $62.4 \%$ of the original dose administered. The approximate cumulative excretion rate over the whole experimental period was calculated using the

Fig. 3 Linear plot (means $\pm \mathrm{SD}$ ) of the ${ }^{3} \mathrm{H}$ urine excretion rate $(\mathrm{pCi} /$ min) versus time (min) (left $y$-axis, $\mathbf{\square}$ ), and cumulative ${ }^{3} \mathrm{H}$ excretion $(\mu \mathrm{Ci})$ in the urine (right $y$-axis, $\mathbf{\Delta})$. Single values were approximated using the calculation of the area under the urine excretion rate vs time curve as described in the text. Inset Cumulative ${ }^{3} \mathrm{H}$ excretion $(\mu \mathrm{Ci})$ in the urine calculated for the first 3.5 days of the experiment $(\boldsymbol{\Delta})$. Single values were approximated using the calculation of the area under the urine excretion rate vs time curve (AUC) as described in the text. The cumulative ${ }^{3} \mathrm{H}$ excretion $(\mu \mathrm{Ci})$ in the urine calculated for the first 3.5 days of the experiment via summation of individual excretion segments is also shown (I). These values were calculated using the following data: time segment $\left(\mathrm{t}_{n}-\mathrm{t}_{n+1}\right)$; total volume $(\mathrm{ml})$ of urine collected $\times$ urine determined $(\mathrm{pCi} / \mathrm{ml})$

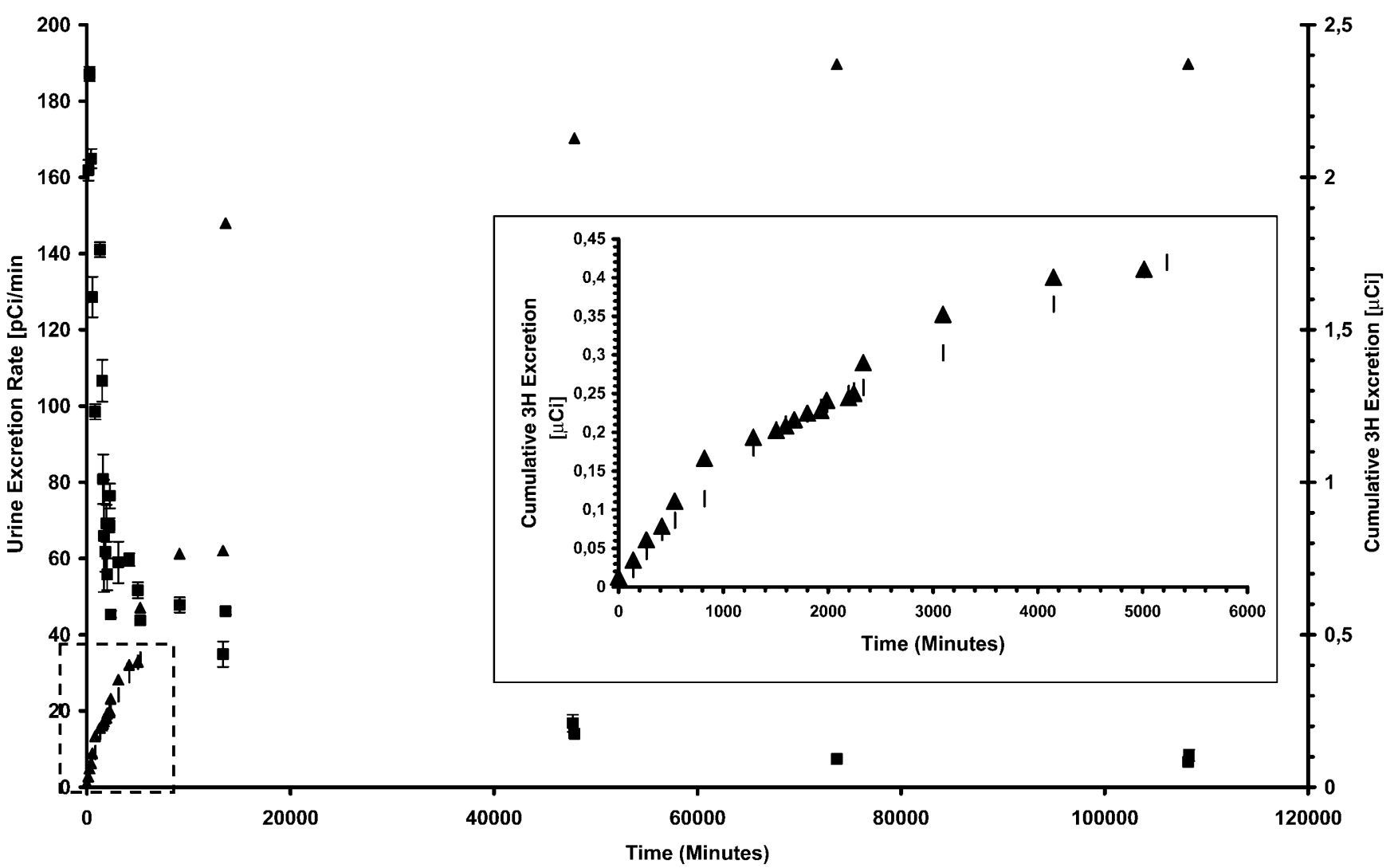

area under the urine excretion rate vs time curve (AUC). The approximation was based on the formula:

$\mathrm{AUC}=\int_{t=0}^{t=\infty} \operatorname{er}^{1} \sum \mathrm{d} t$

where er is the ${ }^{3} \mathrm{H}$ urine excretion rate $(\mathrm{pCi} / \mathrm{min})$. Comparison with the cumulative excretion calculated via multiplication of the radioactivity in the urine $(\mathrm{pCi} /$ $\mathrm{ml}$ ) and the volumes obtained within the first 3.5 days was considered necessary to determine the quality of the AUC approximation. Indeed, within the first 3.5 days close to $100 \%$ of the urine was collected, thus allowing for a close determination of the total amount of radioactivity excreted over this period of time. Comparison of the approximate excretion determined via the AUC with the actual excretion (Fig. 3, inset) demonstrated that estimation of the excretion of radioactivity via the AUC provided an excellent approximation of the actual data.

Comparison of the ${ }^{3} \mathrm{H}$ excretion rate in the urine with the mid-plasma levels of ${ }^{3} \mathrm{H}$-OTA (Fig. 2) allowed an approximation of the renal clearance of radioactivity. Indeed, the slope of the linear regression equaled the average renal clearance of radioactivity, i.e. $\mathrm{Cl}=0.1099 \mathrm{ml} \cdot \mathrm{min}^{-1}$. This clearance was very near the clearance theoretically calculated using the equation for OTA whole body clearance, i.e. $\mathrm{Cl}=\mathrm{V}_{\mathrm{D}} \times \beta$, where $\mathrm{V}_{\mathrm{D}}$ is the volume of distribution $(6.905 \mathrm{l})$ and $\beta$ $\left(0.0195 \mathrm{day}^{-1}\right)$ is the rate constant of the $\beta$ phase (Fig. 1). Using this equation, the whole body clearance for radioactive OTA and metabolites/conjugates was 
$0.0935 \mathrm{ml} \cdot \mathrm{min}^{-1}$, a very close match with the clearance obtained via linear regression (Fig. 2).

Four urine samples were analysed via IAC and HPLC for the presence of parent compound and metabolites. However, in contrast to plasma samples in which most of the radioactivity was found in the methanol fraction, the urine samples were difficult to analyse with IACs because a predominant proportion of the radioactivity was found in the PBS/methanol fraction. In addition, the recovery of unlabeled OTA in the methanol fraction was low. Therefore, whether the radioactivity found in the PBS/methanol fraction consisted of parent OTA and/or metabolites was determined. It was shown by HPLC analysis that most of radioactivity found in the PBS/methanol fraction had the same retention time as the parent OTA, indicating that the observed radioactivity consisted of unchanged OTA and that the IAC column was not functioning properly for urine sample analysis. The amount of unchanged OTA in the urine was, therefore, determined without the use of the IAC. The residue of the chloroform phase was directly taken up in $200 \mu \mathrm{l}$ methanol and $50 \mu \mathrm{l}$ was injected into the HPLC system.

The results of two extractions of each urine sample and the HPLC fractions are shown in Table 3. The fraction distribution obtained for radiolabeled OTA in the urine samples was clearly different from the one obtained with the plasma samples. Indeed, between 33\% and $38 \%$ of the radioactivity was found in the aqueous phase of the urine samples, whereas $<5.0 \%$ activity was found in the aqueous phase of the corresponding plasma samples. To test whether the radioactivity in the aqueous phase of the urine samples was tritiated water and/or OTA metabolite(s), $2 \mathrm{ml}$ of two samples were lyophilized and the radioactivity of the residue as well as of the collected water was determined. The radioactivity found in the residue was $93 \%$ and $87 \%$, respectively, whereas the amount of radioactivity in the water was only $2.2 \%$ and $<4.5 \%$, indicating that the largest proportion of radioactivity was associated with potential OTA metabolite(s) and/or conjugate(s), while little of the activity in the residue was tritiated water. Unfortunately, no enzymatic digestion of the water-soluble fraction with glucuronidase and/or sulphatase was carried out, thus prohibiting determination of whether the water-soluble fraction contained OTA conjugated to glucuronides or sulphates as suggested previously by Castegnaro et al.
(1991) and Kane et al. (1986) or true OTA metabolites (phase I reaction products).

HPLC analyses of the urine chloroform extract revealed that between $42 \%$ and $54 \%$ of the radioactivity coeluted with the OTA standard (retention time 4-6 min, Table 3). An additional activity peak was detected at a retention time of 2-4 min representing between $14 \%$ and $20 \%$ of the total activity in the urine, possibly indicating the presence of OTA metabolite(s) and/or conjugate(s) of either smaller size or higher polarity than the parent compound. This stands in contrast to the situation in plasma where at the corresponding retention time the activity was $<5.0 \%$.

The fraction distribution in the urine described above remained relatively constant over the 9-day period in which urine analysis was possible, indicating that no change in renal handling of OTA in terms of a predominance of a given metabolite or conjugate was detectable throughout the observation period.

\section{Intraindividual fluctuation of OTA plasma levels}

The results from samples from all eight volunteers are shown in Fig. 4a, b. The levels determined ranged between 0.20 and $0.88 \mathrm{ng} / \mathrm{ml}$. Overall, no significant differences between males and females were observed. The time-course of OTA in plasma showed an individual pattern in each volunteer. Female 4 and male 1 showed rather constant plasma levels, while in the other volunteers high plasma OTA variability was found.

A second peak was observed in the HPLC chromatograms primarily of female 1 , but also of females 3 and 4, and of males 2, 3 and 4. This peak was identified by cochromatography as a diastereomer of OTA which has already been reported to be present in roasted coffee (Studer-Rohr et al. 1995). The amount of this diastereomer in the plasma ranged between $10 \%$ and $20 \%$ of the measured concentration of OTA. For the final OTA plasma level, calculation the diastereomer concentration was added to the OTA determined.

\section{Discussion}

Of the total administered radioactivity (radiolabeled OTA), $93 \%$ was found in the plasma and erythrocytes
Table 3 Radioactivity determined in urine samples after extraction and HPLC analysis (bold values indicate the fraction in which OTA was eluted). All values are percentage calculated on the base of the initial value

\begin{tabular}{lcccc}
\hline \multicolumn{5}{c}{ Time after ingestion (days) } \\
\cline { 2 - 5 } & 1 & 2 & 6 & 9 \\
\hline Aqueous phase (after extraction) & 37.8 & 34.8 & 32.5 & 36.3 \\
HPLC time interval (min) & & & & \\
0-2 & $<7.0$ & $<7.0$ & $<7.0$ & $<7.0$ \\
$2-4$ & 19.5 & 20.4 & 14.7 & 13.8 \\
$4-6$ & $\mathbf{4 2 . 3}$ & $\mathbf{4 4 . 5}$ & $\mathbf{5 3 . 7}$ & $\mathbf{4 9 . 9}$ \\
$6-8$ & $<7.0$ & $<7.0$ & $<7.0$ & $<7.0$ \\
$8-10$ & $<7.0$ & $<7.0$ & $<7.0$ & $<7.0$ \\
\hline
\end{tabular}


Fig. 4a, b Individual plasma OTA levels in four male volunteers $\mathbf{a}$ and in four female volunteers b
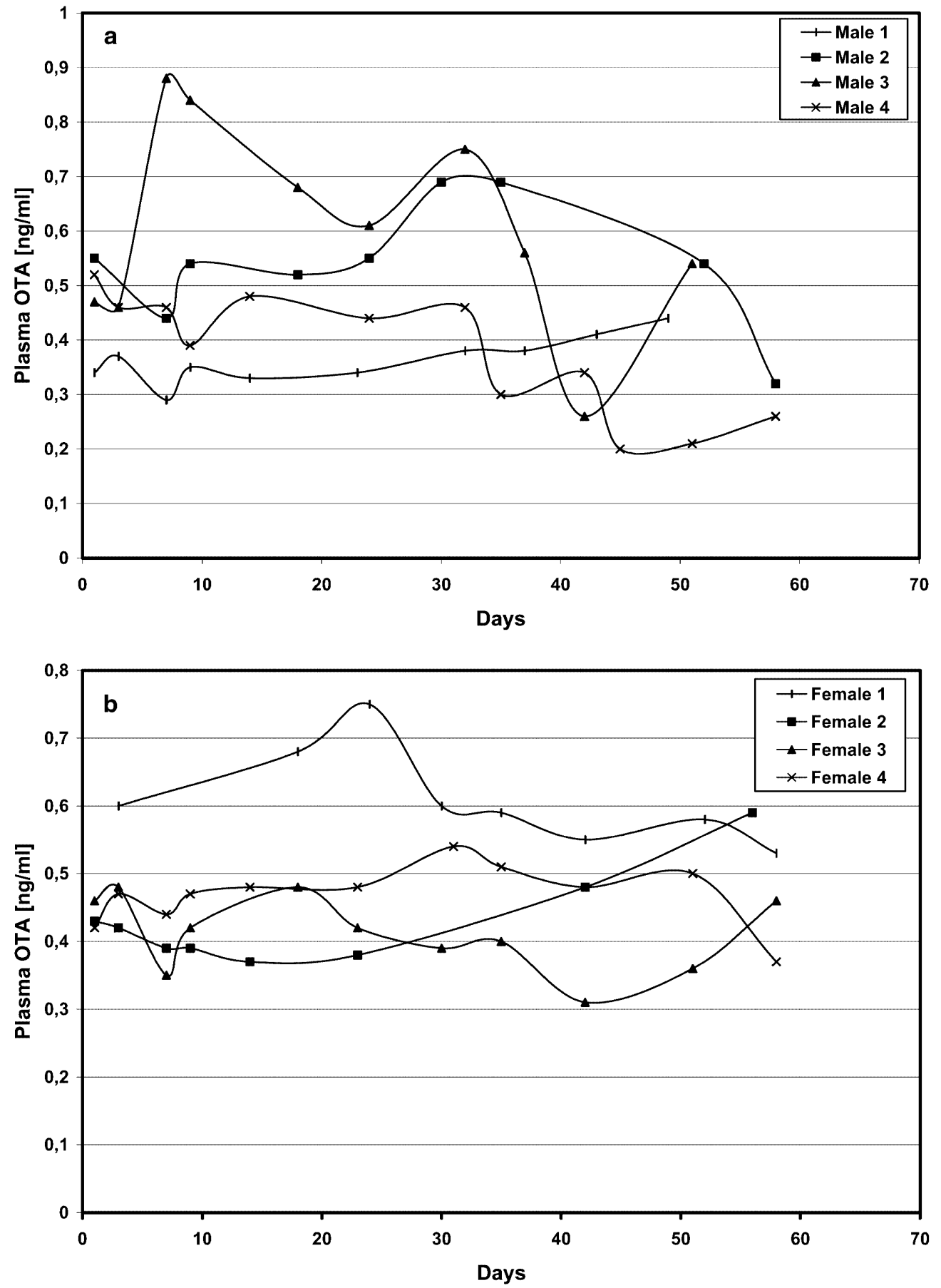

within $8 \mathrm{~h}$ of ingestion. This suggests that the administration of OTA dissolved in ethanol on an empty stomach resulted in a high bioavailability of OTA. The bioavailability of OTA would be expected to be much lower when it is ingested as a food contaminant. Indeed, considerable species differences in the bioavailability and gastrointestinal absorption of orally administered OTA have been reported by Hagelberg et al. (1989), who found, in comparison with OTA administered i.v. dissolved in $51 \mathrm{mM} \mathrm{NaHCO} 3$, only $97 \%, 44 \%$ and $57 \%$ of orally administered OTA in the blood of mice, rats and monkeys, respectively. The distribution of radioactivity between blood corpuscles and plasma in the study presented here demonstrated that over $90 \%$ of the OTA in the blood was in the plasma and approximately $4-10 \%$ in the erythrocytes.

Generally the detection of OTA via IAC/HPLC in plasma samples, as presented in this study, is a relatively simple, reliable and very sensitive method. However, when OTA body burdens or excretion data are required using urine samples, the IAC method is unreliable as OTA recoveries from urine samples varied widely and 
unsystematically. It may well be that some as-yetunidentified components of urine block the antibodies of the column and reduce OTA retention within the column. It is therefore advised that biological samples of varying compositions to be analysed for OTA via IAC should first be tested for the applicability of IAC with spiked samples.

The results of the kinetic experiment (Fig. 1) indicated that the elimination of OTA from the blood was best described by a two-compartment model consisting of a central compartment. In the $\alpha$ or distribution phase, which lasted about 6 days, the radioactivity $\left({ }^{3} \mathrm{H}\right.$-OTA) in the plasma decreased rapidly by $1.83 \mu \mathrm{Ci}$, whereas in the same time period only $0.77 \mu \mathrm{Ci}$ (radioactivity of ${ }^{3} \mathrm{H}$ representing either parent ${ }^{3} \mathrm{H}$-OTA, ${ }^{3} \mathrm{H}$-OTA-conjugates or ${ }^{3} \mathrm{H}$-OTA-metabolites, but only negligible amounts of ${ }^{3} \mathrm{H}_{2} \mathrm{O}$ ) were excreted via urine. These figures appear to demonstrate that during the first 6 days OTA is mainly distributed within the body and only a minor fraction is excreted. During the following 69 days of the $\beta$ or elimination phase, the level of plasma radioactivity decreased further by $0.97 \mu \mathrm{Ci}$, while within the same time period $1.61 \mu \mathrm{Ci}$ was excreted via the urine. Comparison with the data points and slope of the linear regression obtained by plotting the urinary excretion rate $(\Delta \mathrm{U} / \Delta t)$ over a time period $(\Delta \mathrm{T})$ versus the mid-plasma concentrations of OTA (Fig. 2), concurred with the theoretical whole-body clearance rate of $0.0935 \mathrm{ml} \cdot \mathrm{min}^{-1}$ calculated. This plot and the calculations of the renal clearance (slope of the regression curve) also demonstrate higher and lower than expected clearance rates for high and low OTA plasma concentrations, respectively, which could be interpreted as representing a filtrationmediated reabsorption process with low capacity. At high OTA plasma concentrations the reabsorption is saturated leading to excretion rates greater than anticipated (points above the linear regression, Fig. 2), while at low OTA plasma concentrations reabsorption causes the excretion rate to be less than anticipated (points above the linear regression, Fig. 2). OTA reabsorption in the kidney was also suggested by the fact that the overall clearance for OTA was much lower than clearance of freely filterable nonreabsorbable inulin (Hagelberg et al. 1989).

The elimination half-life ( $\beta$ phase) of OTA was calculated to be 35.5 days. This is in line with the elimination half-lives of OTA in monkeys of 21.3 or 35 days after oral and i.v. administration, respectively (Hagelberg et al. 1989). The long elimination half-lives stand in contrast to the considerably shorter half-lives of OTA of $40 \mathrm{~h}$ in mice (Fukui et al. 1987; Hagelberg et al. 1989), 55-120 h in rats, (Ballinger et al. 1986; Galtier et al. 1979; Hagelberg et al. 1989) and $72-120 \mathrm{~h}$ in pigs (Galtier et al. 1981; Mortensen et al. 1983). Species differences in OTA uptake from the gastrointestinal tract, distribution (specific plasma proteins and thus binding capacities of OTA) and metabolism may be the physiological factors limiting OTA elimination (Fuchs 1988; Hagelberg et al. 1989). Therefore, species differ- ences in terminal half-lives of OTA would be expected. Indeed, using allometric relationships between mice, rats and humans, the ratios being 1:2.1:14.1, based on body weight, volume and surface area, a more rapid uptake, metabolism and elimination of OTA would be expected (Van Straalen 1996). Based on these allometric relationships and using the mouse as the standard, terminal half-lives of OTA of $40 \mathrm{~h}, 84 \mathrm{~h}$ and $564 \mathrm{~h}$ (23.5 days) for mice, rats and humans, respectively, would be suggested. The latter values are indeed not very far from those determined experimentally in this and previous studies. However, the half-life comparison as well as the detailed investigation of the kinetic parameters, e.g. clearance rates, also indicate that there are additional factors other than body size and volume etc. (e.g. OTA protein binding to species-specific proteins, OTA reabsorption in the kidney) that govern the elimination of OTA.

In the plasma, most of the radioactivity $(>80 \%)$ was identified as unchanged OTA, whereas in the urine only between $42 \%$ and $54 \%$ of the radioactivity was recognized as unchanged OTA. Around $33 \%$ of the radioactivity was found in the aqueous phase after extraction and around $14-20 \%$ in the HPLC fraction before the OTA was eluted (2-4 min). In the four urine samples analysed (on days 1, 2,6 and 9) these values remained relatively constant. Urine samples from later time-points could not be analysed by HPLC as the amount of radioactivity was too low. Although these metabolites and/or conjugates were not further identified, it was shown by lyophilization that the radioactivity found in the aqueous phase was not tritiated water.

The fact that at best only small concentrations of metabolites and/or conjugates were detected in the plasma while about $50 \%$ of the radioactivity in the urine was not parent OTA but rather OTA metabolites and/or OTA conjugates, suggests that OTA metabolism and/or conjugation may play a significant role in the mechanisms underlying the aetiology of BEN and UTT in humans. Indeed, previous studies have demonstrated the importance of the conversion of OTA in the kidney by the action of cytochrome P-450 enzymes to 4-hydroxyOTA in rats and the resistance/susceptibility to renal tumors (Castegnaro et al. 1998; IARC 1993; Stein et al. 1985). Poor metabolizing rat strains (e.g. Dark-Agouti females not metabolizing OTA to 4-hydroxy-OTA) appear resistant to OTA-induced renal tumors, whereas extensive and/or moderate metabolizers appear more susceptible to tumor induction (Castegnaro et al. 1998), thus indicating that the metabolism of OTA to 4-hydroxy-OTA may play a critical role in OTA-induced renal carcinogenesis, at least in rats. In contrast, comparison of the half-lives of OTA and OTA conjugates and metabolites in rats clearly demonstrated that the parent compound OTA had the longest half-life, while all other structural variants and metabolites/conjugates were excreted three to four times faster (Ballinger et al. 1986; Galtier et al. 1979; Hagelberg et al. 1989).

Furthermore, it has been shown in numerous studies, in vitro and in vivo, that indeed little toxicity can be 
attributed to OTA metabolites or conjugates, while all the toxicity resides with the parent compound (OTA). In consequence, one would expect that fast metabolism in rats leads to an efficient and rapid elimination of OTA and thus to a lower acute and chronic toxicity or tumorigenicity. The discrepancies between the study presented by Castegnaro et al. (1998) and toxicity and kinetic studies in other strains of rats, demonstrate the difficulties in extrapolating from the rodent model to humans. Unfortunately, there are no kinetic data on OTA handling in Dark-Agouti and Lewis rats, which would allow a comparison with other rat strains, and thus could explain the low susceptibility of female Lewis rats to OTA-induced tumors despite their extensive metabolizer status for OTA.

Based on the experimentally determined half-life and the estimated body burden of OTA, the daily intake under steady-state conditions can be calculated from the equation intake $=\left(\mathrm{k}_{\mathrm{el}} \times\right.$ body burden $) / \mathrm{f}$ (Klaassen 1986), where $\mathrm{k}_{\mathrm{el}}$ is the elimination constant (0.0461) and $\mathrm{f}$ is the fraction absorbed. The body burden in humans has been estimated based on the assumption that the same organ distribution of OTA exists in humans as in pigs, and the following relative OTA organ concentrations, expressed as percent of the serum concentration, were found (Kühn 1993): 7.3\% in kidney, 6.9\% in liver, $4.7 \%$ in fat and $3.8 \%$ in muscle. Assuming an average plasma level of $0.4 \mathrm{ng} / \mathrm{ml}$ in humans, a central compartment volume of $3000 \mathrm{ml}$ and an approximate blood corpuscle OTA concentration of $10 \%$ of the plasma concentration, an approximate body burden can be derived. The total plasma OTA would be $1200 \mathrm{ng}$ OTA. The body burden would be $137 \%$ of the plasma OTA burden, i.e. $1200 \mathrm{ng}$ OTA $\times 1.37(7.3 \%$ in kidney, $6.9 \%$ in liver, $4.7 \%$ in fat and $3.8 \%$ in muscle, $10 \%$ in blood corpuscles) resulting in an approximate body burden of $1.644 \mu \mathrm{g}$ OTA.

Thus, the calculated daily intake is $95 \mathrm{ng} /$ person or $1.53 \mathrm{ng} / \mathrm{kg}$ body weight (f approximately $80 \%$, based on the human volunteer in this study with a body weight of $62 \mathrm{~kg}$ ), which is very well in line with the daily intake calculated from food consumption data and the respective concentrations found in food items (80-160 ng) (DFG 1990; Studer-Rohr et al. 1995). However, considering the potential differences between pigs and humans with regard also to OTA plasma protein binding it may well be that the organ distribution is substantially different between these species. This would suggest that the body burden could be higher, but also lower, than calculated above and therefore body burden and OTA intake calculations should be approached cautiously when extrapolating from animal data.

The OTA half-life determined in a human volunteer in this study was 6-13-fold longer than the half-lives reported in rats. A tenfold higher plasma level in humans than in rats, resulting from the same oral intake levels per kilogram body weight, would therefore be expected. This has been experimentally confirmed by Rásonyi (1996) and should taken into account in future human risk assessments. The long half-life of OTA in humans, as suggested by this study with a single volunteer, must be especially taken into consideration when cancer risk extrapolations are being carried out based on the rat cancer bioassay (Boorman 1989). Furthermore, when considering the large sex differences in renal tumor incidence between male and female rats in the rat cancer bioassays (Boorman 1989; Castegnaro et al. 1998), the question arises as to whether or not sex differences pertaining to OTA plasma levels, OTA kinetics and cancer susceptibility may also prevail in humans.

Current epidemiological data from the endemic BEN region in eastern Europe do not indicate a higher susceptibility of males or females to either BEN or UTT (Radovanovic 1991; Sostaric and Vukelic 1991). However, whether or not the right parameters were assessed to detect such differences remains an open question. Indeed, the OTA plasma levels of four male and four female volunteers investigated in the study presented here are in line with previous data reported by BAG (1994), Breitholz-Emanuelsson et al. (1993, 1994), and Palli et al. (1999) (Table 1). The high variability of OTA plasma levels found in some of the volunteers during the 8-week observation period (Fig. 4a, b) indicates that for the determination of representative individual OTA plasma levels, a single analysis is not sufficient. Peak OTA plasma concentrations reflecting $\alpha$ phase kinetics may be induced shortly after the consumption of food items containing high levels of OTA. Although the volunteers in the present study did not record their nutritional habits, male 3 reported the consumption of dried fruits which might explain the steep increase in OTA plasma levels between day 4 and day 7 , as dried fruits are known to contain high concentrations of OTA (Baumann and Zimmerli 1988; Steiner et al. 1993; Zohri and Abdel-Gawad 1993). Relatively steep drops in OTA plasma levels as shown by males 2,3 and 4 and by females 3 and 4 may be explained by the $\alpha$ phase distribution of OTA into the organs after above average ingestion of OTA. On the other hand, intraindividual variability in OTA kinetics may have prevailed resulting from nutritionally or hormonally derived changes in specific OTA binding plasma protein species and respective protein concentrations.

The existence of a diastereomer of OTA was detected during the preparation of pure OTA after heating by Rásonyi (1996) and subsequently this diastereomer has also been found in roasted but not in green coffee beans (Studer-Rohr et al. 1995). The detection of the OTA diastereomer in human plasma is described here for the first time. The subject with the highest levels of diastereomer (female 1) was a strong coffee consumer. As the diastereomer was detected not only in the plasma of volunteers who did drink coffee, dietary sources other than coffee must be present.

In summary, a very long half-life of OTA was determined in a human volunteer. In view of the current knowledge on the presence of OTA in the human diet, the toxicity and carcinogenicity of OTA and the data 
presented here, caution is advised when risk assessments are carried out based only on animal bioassay data.

Acknowledgements Sincerest thanks go to Professor Christian Schlatter for ongoing support of this project. We would like to thank Dr. Joan Tarloff, University of the Sciences in Philadelphia, Department of Pharmacology and Toxicology, and Dr. John Pritchard, NIEHS-RTP, for helpful suggestions, critical evaluation of the kinetics data and especially for reviewing the manuscript in general. This study was made possible by support from the Swiss Federal Office of Public Health, grant FE 316-91-334.

\section{References}

BAG (1994) Tätigkeitsbericht der Abteilung Vollzug Lebensmittelrecht und Lebensmittelwissenschaft des Bundesamtes für Gesundheitswesen 1993, Abteilung Lebensmittelwissenschaften, Sektion Lebensmittelchemie, c) Ochratoxin in Humanblutserum. Mitt Gebiete Lebensm Hyg 85: 428-429

Ballinger MB, Phillips TD, Kubena LF (1986) Assessment of the distribution and elimination of ochratoxin a in the pregnant rat. J Food Safety 8: 11-24

Bauer J, Gareis M (1987) Ochratoxin A in der Nahrungsmittelkette. J Vet Med 34: 613-627

Baumann U, Zimmerli B (1988) Einfache Ochratoxin A-Bestimmung in Lebensmitteln. Mitt Gebiete Lebensm Hyg 79: $151-158$

Boorman GA (1989) Toxicology and carcinogenesis studies of ochratoxin A in F344/N rats. NTP Technical Report NTP TR 358

Breitholz A, Olsen M, Dahlbäck A, Hult K (1991) Plasma ochratoxin A levels in three Swedish populations surveyed using an ion-pair HPLC technique. Food Addit Contam 8: 183-192

Breitholz-Emanuelsson A, Olsen M, Oskarsson A, Palminger I, Hult K (1993) Ochratoxin A in cow's milk and in human milk with the corresponding human blood samples. J Assoc Off Anal Chem 76: 842-846

Breitholz-Emanuelsson A, Minervini F, Hult K, Visconti A (1994) Ochratoxin A in human serum samples collected in southern Italy from healthy individuals and individuals suffering from different kidney disorders. Nat Toxins 2: 366-370

Castegnaro M, Maru V, Petkova-Bocharova T, Nikolov I, Bartsch H (1991) Concentrations of ochratoxin A in the urine of endemic nephropathy patients and controls in Bulgaria: lack of detection of 4-hydroxyochratoxin A. In: Castegnaro M, Plestina R, Dirheimer G, Chernozemsky IN, Bartsch H (eds) Mycotoxins, endemic nephropathy and urinary tract tumours (IARC Scientific Publications, vol 115). International Agency for Research on Cancer, Lyon, pp 165-169

Castegnaro M, Mohr U, Pfohl-Leskowicz A, Estève J, Steinmann J, Tillmann T, Michelon J, Bartsch H (1998) Sex- and strain-specific induction of renal tumors by ochratoxin $\mathrm{A}$ in rats correlates with DNA adduction. Int J Cancer 77: 70-75

Chang FC, Chu FS (1977) The fate of ochratoxin A in rats. Food Cosmet Toxicol 15: 199-204

DFG (1990) Ochratoxin A, Vorkommen und toxikologische Bewertung. Deutsche Forschungsgemeinschaft, DFG

Frohlich AA, Marquardt RR, Ominski KH (1991) Ochratoxin $A$ as a contaminant in the human food chain: a Canadian perspective. In: Castegnaro $M$, Plestina $R$, Dirheimer $G$, Chernozemsky IN, Bartsch $\mathrm{H}$ (eds) Mycotoxins, endemic nephropathy and urinary tract tumors (IARC Scientific Publications, vol 115). International Agency for Research on Cancer, Lyon, pp 139-143

Fuchs R (1988) Distribution and fate of ochratoxin A in experimental animals. Doctoral Thesis, Uppsala, Sweden

Fukal L, Reisnerova H (1990) Monitoring of aflatoxins and ochratoxin A in Czechoslovak human sera by immunoassay. Bull Environ Contam Toxicol 44: 345-349
Fukui Y, Hoshino K, Kameyama Y, Yasui T, Toda C, Nagano H (1987) Placental transfer of ochratoxin A and its cytotoxic effect on the mouse embryonic brain. Food Chem Toxicol 25: 17-24

Galtier P, Charpenteau JL, Alvinerie M, Labouche C (1979) The pharmacokinetic profile of ochratoxin $\mathrm{A}$ in the rat after oral and intravenous administration. Drug Metab Dispos 7: 429434

Galtier P, Alvinerie M, Charpenteau JL (1981) The pharmacokinetic profiles of ochratoxin A in pigs, rabbits and chickens. Food Cosmet Toxicol 19: 735-738

Golinski P, Grabarkiewicz-Szczesna J, Chelkowski J, Hult K, Kostecki M (1991) Possible sources of ochratoxin A in human blood in Poland. In: Castegnaro M, Plestina R, Dirheimer G, Chernozemsky IN, Bartsch $\mathrm{H}$ (eds) Mycotoxins, endemic nephropathy and urinary tract tumors (IARC Scientific Publications, vol 115). International Agency for Research on Cancer, Lyon, pp 153-158

Hagelberg S, Hult K, Fuchs R (1989) Toxicokinetics of ochratoxin $\mathrm{A}$ in several species and its plasma-binding properties. J Appl Toxicol 9: 91-96

Hald B (1991) Ochratoxin A in human blood in European countries. In: Castegnaro $M$, Plestina $R$, Dirheimer $G$, Chernozemsky IN, Bartsch $\mathrm{H}$ (eds) Mycotoxins, endemic nephropathy and urinary tract tumors (IARC Scientific Publications, vol 115). International Agency for Research on Cancer, Lyon, pp 159-164

Hult K, Plestina R, Habazin-Novak V, Radic B, Ceovic S (1982) Ochratoxin A in human blood and Balkan endemic nephropathy. Arch Toxicol 51: 313-321

IARC (1993) Ochratoxin A. In: IARC, WHO (eds) Some naturally occurring substances: food items and constituents, heterocyclic aromatic amines and mycotoxins (IARC Monographs on the evaluation of carcinogenic risks to humans, vol 56). International Agency for Research on Cancer, WHO, Lyon, pp 489-521

Kane A, Creppy EE, Roth A, Röschenthaler R, Dirheimer G (1986) Distribution of the [3H]-label from low doses of radioactive ochratoxin A ingested by rats, and evidence for DNA single-strand breaks caused in liver and kidneys. Arch Toxicol 58: $219-224$

Klaassen CD (1986) Distribution, excretion, and absorption of toxicants. In: Klaassen CD, Amdur MO, Doull J (eds) Casarett and Doull's toxicology. The basic science of poisons. Macmillan Publishing Company, New York, pp 33-66

Kühn I (1993) Quantitative Untersuchungen zum Transfer und zur Elimination von Ochratoxin A bei wachsenden Schweinen nach langfristiger oraler Applikation. Landbauforschung Völkenrode, Sonderheft 137: 1-100

Kuiper-Goodman T, Scott PM (1989) Risk assessment of the mycotoxin ochratoxin A. Biomed Environ Sci 2: 179-248

Li S, Marquardt RR, Frohlich AA, Vitti TG, Crow G (1997) Pharmacokinetics of ochratoxin A and its metabolites in rats. Toxicol Appl Pharmacol 145(1): 82-90

Mortensen HP, Hald B, Larsen AE, Madsen A (1983) Ochratoxin A contaminated barley for sows and piglets. Acta Agric Scand 33: $349-352$

Nikolov IG, Petkova-Bochavora D, Castegnaro M, Pfohl-Leskowicz A, Gill C, Day N, Chernozemsky IN (1996) Molecular and epidemiological approaches to the etiology of urinary tract tumors in an area with Balkan endemic nephropathy. J Environ Pathol Toxicol Oncol 15(2-4): 201-207

Palli D, Miraglia M, Saieva C, Masala G, Cava E, Colatosti M, Corsi AM, Russo A, Brera C (1999) Serum levels of ochratoxin $\mathrm{A}$ in healthy adults in Tuscany: correlation with individual characteristics and between repeat measurements. Cancer Epidemiol Biomarkers Prev 8(3): 265-269

Petkova-Bocharova T, Chernozemsky IN, Castegnaro M (1988) Ochratoxin A in human blood in relation to Balkan endemic nephropathy and urinary systems tumours in Bulgaria. Food Addit Contam 5: 299-301

Radovanovic Z (1991) Epidemiologic characteristics of Balkan endemic nephropathy in eastern regions of Yugoslavia. In: 
Castegnaro M, Plestina R, Dirheimer G, Chernozemsky IN, Bartsch $\mathrm{H}$ (eds) Mycotoxins, endemic nephropathy and urinary tract tumors (IARC Scientific Publications, vol 115). International Agency for Research on Cancer, Lyon, pp 159-164

Rásonyi T (1996) Mechanistic investigations in ochratoxin A induced nephrotoxicity and the relevance for the sex specific renal tumor induction in rats. Dissertation of the Swiss Federal Institute of Technology ETH no. 11343

Rühl C, Weber R, Jiao Y (1992) Ochratoxin A Aufnahme mit Cerealien. Tätigkeitsbericht Bundesgesundheitsamt 1991: 214-215

Sostaric B, Vukelic M (1991) Characteristics of urinary tract tumors in the area of Balkan endemic nephropathy in Croatia. In: Castegnaro M, Plestina R, Dirheimer G, Chernozemsky IN, Bartsch H (eds) Mycotoxins, endemic nephropathy and urinary tract tumors (IARC Scientific Publications, vol 115). International Agency for Research on Cancer, Lyon, pp 29-35

Stein AF, Phillips TD, Kubena LF, Harvey RB (1985) Renal tubular secretion and reabsorption as factors in ochratoxicosis: effects of probenecid on nephrotoxicity. J Toxicol Environ Health 16: 593-605

Steiner W, Brunschweiler K, Leimbacher E, Schneider R (1993) Aflatoxine B1 und G1, Cyclopiazonsäure, Kojisäure und
Ochratoxin A in Trockenfeigen mit BGY-Fluoreszenz. Mitt Gebiete Lebensm Hyg 84: 523-526

Studer-Rohr J (1995) Ochratoxin A in humans: exposure, kinetics and risk assessment. Dissertation of the Swiss Federal Institute of Technology ETH no. 11071

Studer-Rohr J, Dietrich DR, Schlatter J, Schlatter C (1995) The occurrence of ochratoxin A in coffee. Food Chem Toxicol 33: $341-355$

Trucksess MW, Giler J, Young K, White KD, Page SW (1999) Determination and survey of ochratoxin $\mathrm{A}$ in wheat, barley, and coffee - 1997. J AOAC Int 82(1): 85-89

Van Straalen N (1996) Ecotoxicology. In: Niesink RJM, de Vries J, Hollinger MA (eds) Toxicology, principles and applications. CRC Press, Boca Raton, pp 1112-1139

Zimmerli B, Dick R (1995) Determination of ochratoxin A at the ppt level in human blood, serum, milk and some foodstuffs by high performance liquid chromatography with enhanced fluorescence detection and immunoaffinity cleanup: methodology and Swiss data. J Chromatogr B Biomed Appl 666: 85-99

Zohri AA, Abdel-Gawad KM (1993) Survey of mycoflora and mycotoxins of some dried fruits in Egypt. J Basic Microbiol 33: $279-288$ 